\title{
APPRECIATING JOHANN M. SCHEPERS
}

\author{
FREDDIE CROUS \\ with \\ GIDEON P. DE BRUIN \\ GERT ROODT \\ LEON VAN VUUREN \\ Department of Human Resource Management \\ University of Johannesburg \\ WILLEM J. SCHOEMAN \\ ANITA D. STUART \\ Department of Psychology \\ University of Johannesburg
}

\begin{abstract}
As an expert leader in psychometrics, eminent scholar, gatekeeper, study leader and mentor, Johann M. Schepers has had a profound effect on the development of Psychology and Industrial Psychology in South Africa. By means of an appreciative inquiry the outstanding ability of this man has been highlighted in stories which resulted in a rich profile and a legacy that needs to be protected and nurtured.
\end{abstract}

"[A]ppreciation is a better mode for the understanding of achievement than are all the analytical kinds of accounting for the emergence of exceptional individuals".

Key words

Harold Bloom, 2002, p.5

Appreciative inquiry, expert leader, psychometrics

As a young research officer Johann Schepers found his niche in psychometrics. From 1957 to 1959 his skills in this area were honed at Princeton University, where he studied under scholars of renown in the field of psychometrics such as Harold Gulliksen and Ledyard R Tucker. After passing the general doctoral examination specialising in psychometrics he returned to South Africa to continue a career that has had a profound influence on the development of the field in this country. As leader of the Psychometric Programme and head of its Psychometric Division he formed part of an exceptional team under the leadership of Simon Biesheuvel, who established the National Institute for Personnel Research (NIPR) of the Council for Scientific and Industrial Research (CSIR) as a world-class research institution which was internationally acclaimed.

Over 16 years as a full-time researcher in psychometrics, first at the National Bureau of Educational and Social Research and later at the NIPR, the quality of his outputs was of such a high standard that in 1970 he was appointed professor of psychometrics at the University of South Africa. In 1976 he was invited to become chair of the Department of Psychology at the Rand Afrikaans University (now known as the University of Johannesburg) - a position he held until 1982. In 1990 he was appointed professor in psychometrics, this time in the Department of Industrial Psychology (which subsequently became the Department of Human Resource Management). This is still the only chair in psychometrics in the Republic of South Africa.

His more than 100 publications (including four books), 14 technical reports and 22 psychometric tests have established Johann Schepers as a research leader. Gardner, Csikszentmihalyi and Damon (2001) regard such scientists as creator leaders who generate and codify the necessary specialised knowledge in order to establish and expand domains such as Psychology and Industrial Psychology. His specialist knowledge of psychometrics enabled him to do outstanding research especially (but not exclusively) in areas such as mental ability, personality, perception and evoked potentials of the brain.
As a prominent member of the fields* of Psychology and Industrial Psychology Johann Schepers has occupied the elite role of gatekeeper. (Presiding over the destiny of a discipline and judging which changes in the domain should be sanctioned, is the function of a gatekeeper.) In 1974 he became a member of the first Professional Board for Psychology of the South African Medical and Dental Council, and five years later he joined the second Professional Board. He was a member of the Psychometrics Committee of the Professional Board for Psychology from 1996 to 2001, and also in 2003. For three years he served on the discipline-oriented Executive Committee for Psychology and Communication Science at the Human Sciences Research Council (HSRC), and from 1984 to 1992 he was scientific advisor to the Institute for Psychological and Edumetric Research of the HSRC. From 1985 to 1992 he also served on the Department of Manpower's Research and Development Committee.

Johann Schepers has received wide-spread recognition from other gatekeepers of the field of Psychology/Industrial Psychology. His recent awards are:

- Colours from the Rand Afrikaans University for outstanding academic achievement (1992)

- An award from the Department of Human Resources Management for academic excellence (1992)

- The President's Award from the Psychological Association of South Africa for his contribution to Psychology (1993)

- The Stals Prize for Psychology from the South African Academy for Science and Arts (1994)

- Extraordinary fellowship of the Society for Industrial and Organisational Psychology of South Africa.

A vital field always requires approved students (Gardner et al., 2001). Under the guidance of Johann Schepers, 67 Master's and 18 doctoral degree students completed their studies in either Psychology or Industrial Psychology. The acknowledgement Susan O'Hara (1985) included in her doctoral dissertation for her promoter, Johann Schepers, is representative of the high esteem in which he is held by his students: 
It is impossible to put into words the gratitude I feel toward Prof Johann M. Schepers for his generous help and support in promoting this thesis. He agreed to guide my research, knowing little about me, and was readily accessible and unfailingly kind and patient. He consistently gave thoughtful and thorough help during the three and one-half years he was involved in this project. As an American in a university where I did not understand the language, he did much to smooth my way, even translating documents which I could not read. I shall attempt to repay the debt I feel by performing with dignity, compassion and humility the profession of psychologist - as he does (p. iii).

The aforementioned bears testimony to his influence on the domains and fields of Psychology and Industrial Psychology. A person who strongly influences others may be regarded as a master in his field (Bloom, 2002). As expert leader, eminent scholar, gatekeeper, study leader and mentor, Johann Schepers may therefore be considered as such. Is it possible to illustrate the core that represents his unique contribution? Bloom (2002) suggests that appreciation is the best mode for understanding outstanding ability. By appreciating that which makes Johann Schepers extraordinary it is possible to construct the positive core inherent to him (Cooperrider, Whitney \& Trosten-Bloom, 2003). Appreciating Johann Schepers has the potential to bring to light his exceptional legacy which in turn may challenge us to renew the domains of Psychology and Industrial Psychology, since a positive image evokes positive actions (Cooperrider, 1999). Inquiring into the mastery of another may therefore stimulate positive change. There are clearly several ways in which the contribution of such a scholar of distinction can be appreciated. For the purpose of this paper it was decided to conduct a type of peer review inquiry.

\section{INQUIRY DESIGN}

The appropriate research approach with which to understand the essence of Johann Schepers' outstanding ability would be an appreciative inquiry (Cooperrider et al., 2003) since this positive form of action research focuses on the search for and study of those "life-giving forces" present in a human system when it functions at its best (Whitney \& Trosten-Bloom, 2003). It is in connecting to this positive core that change is made possible (Cooperrider et al., 2003). Appreciative inquiry forms part of the new field of study in the organisational sciences, the field of positive organisational scholarship (Cameron, Dutton \& Quinn, 2003).

The focus of this kind of inquiry is on data collection which chooses the positive (Watkins \& Mohr, 2001) by means of asking 'the unconditional positive question' (Ludema, Cooperrider \& Barrett, 2001). However, the data is collected in the form of stories rather than via traditional quantitative, analytic methods (Watkins \& Mohr, 2001). A central premise of appreciative inquiry is that this deliberate positive process of knowing is socially constructed. In other words, the creation of meaning takes place through dialogue (Cooperrider et al., 2003). Appreciation is an affectionate, absorbing endeavour that requires the investment of both cognitive and emotional energy (Cooperrider et al., 2003). As such "it may judge, but always with gratitude, and frequently with awe and wonder" (Bloom, 2002, p. 5). Appreciation elevates (Haidt \& Kelyner, 2004), which in turn generates elevated observations followed by elevated emotions (Cooperrider \& Avital, 2004) which broaden the minds (Fredrickson, 2003) of those involved in the appreciative inquiry process. As such it opens up the possibility for positive change.

The dominant approach to the appreciative inquiry process is the Four-D Model (Cooperrider et al., 2003). The four key phases in this process are: The Discovery phase (the best of what is); the Dream phase (envisioning); the Design phase (modeling); and the Destiny phase (sustaining). Six colleagues, of whom two are former doctoral students (WS and AS) participated in this collaborative inquiry. We had to improvise the process since appreciative inquiry has its origins in Organisation Development and Change (Cooperrider \& Srivastva, 1987); keeping in mind that it is in the encounter with Johann Schepers that change is made possible (Madeline \& Martin, 2006), focusing on him as the affirmative topic choice (Cooperrider et al., 2003). To our knowledge this is the first appreciative inquiry done on a person. For the Discovery phase interviews were conducted in pairs, inquiring into profound stories originating from engagements with Johann Schepers. The short interview protocol prepared for this exercise was based on the Encyclopedia of Positive Questions compiled by Whitney, Cooperrider, Trosten-Bloom and Kaplin (2002). Subsequently, we "mined" the data (Watkins \& Mohr, 2001) by identifying those themes emanating from the stories that represent the 'positive core' of Johann Schepers. For the Dream phase each of us separately created a positive image of the man based on those themes. This was integrated into a shared image in the form of a profile. For the Design phase we constructed his legacy for the field of Psychology/Industrial Psychology so as to inspire others to make his legacy our Destiny.

\section{INQUIRY OUTCOMES}

Due to space limitations it is impossible to capture in full the richness of each interview. Nevertheless, the original story and comments prepared for the interviews are depicted in Table 1.

TABLE 1

RESPONSES TO APPRECIATIVE INQUIRY INTERVIEW QUESTIONS

1. Tell me of a meaningful encounter you had with Johann Schepers. What made this a profound experience?

LvV: I once had to discuss a Master's degree student's statistical analysis with him. In passing he mentioned the validity coefficients of another student of mine. He could recall the validity coefficients to three decimals. Note that this was about a year after the statistical analysis had been conducted.

AS: Prof Johann never forgets his students and remembers their research studies and findings. He reminded me, just a few weeks ago, of an (unpublished) study I had the opportunity to discuss with him many years ago. The study was about the cognitive skill of homosexual men with high versus low testosterone levels and presented interesting findings which could easily be answered for theoretically. Prof Johann keenly inquired whether the study was ever published or not, encouraging me (along with my student) to publish the findings in the interest of science, and making suggestions about further studies which could broaden the topic immensely. That is how I will remember Prof Johann ... interested professional, encouraging, gentle with an especially sharp intellect. The university has many intelligent people with outstanding publication records, but there are few that reach the highest levels without arrogance - always maintaining simplicity, modesty, warmth and genuine intellectual interest.

DdB: Some of my most meaningful encounters with Prof Johann have been in his lounge when he is in a relaxed mood and our discussions have diverged from psychological matters. In these discussions his deep knowledge of topics as varied as the Bible, history, and geometry became apparent and showed that he is a scholar with wide interests and profound insight into matters beyond the borders of psychology. Prof Johann once explained something to me that he had read in a book entitled The Bible Code. The book contained some Hebrew text. Without looking up from the book he asked me in a matter-of-fact tone of voice "Jy lees mos Hebreeus, né?" This experience has stuck in my mind because it illustrates something of his roundedness and versatility as an academic and scholar. He takes it for granted, without being arrogant, that an academic scholar should have a broad general knowledge, including the ability to read and write ancient languages!

GR: I recall an incident where Prof Schepers and I had a discussion on Drosnin's The Bible Code. He impressed me as a scholar who can read and write Hebrew. As a person with a profound knowledge of mathematics he was intensely interested in the formulae researchers applied for deciphering the Bible code. As in so many other spheres in life, he also approached this as a 'research problem' by verifying the formulae and mathematical procedures. This incident illustrates his questioning and critical approach to typical 'life problems'. For me his immense theological knowledge and his deep-rooted faith stand out. 
WS: While I was writing up my doctoral dissertation, Johann Schepers read through my work. The outcome was: "What do you think happened here?" (he was referring to my results), and "What do you think will happen if we do the following? Now go and do it!" This process repeated itself three to four times, whereupon I asked: "Prof Schepers, when is it enough for a PhD?" His answer: "It was enough long ago - research is much bigger than a PhD." With these words he emphasised that the life of Johann Schepers is encapsulated in research, which he executes with honesty and a deep sincerity

FC: As a Master's student I wanted to do research in the domain of Consumer Psychology. I specifically wanted to study the cognitive style, field dependence/independence in relation to consumer decision making. As I began reading up on the topic, I was surprised to find that the person responsible for designing the most sophisticated instruments to measure this kind of cognitive orientation was to be found not in the United States of America, but at the Rand Afrikaans University (now the University of Johannesburg), where I was a student! I subsequently rushed to the Department of Psychology, of which he was the chairperson. The secretary was not in her office, but his door was open. I hesitantly entered his office, only to be invited in, in the most welcoming manner. To this day I recall our meeting. I was struck not only by his intelligence and eloquence, but by his sincerity and utter decency. He immediately grasped the essence of my question and referred me to a doctoral research study on cognition in advertising, which provided me with the "link" I had been looking for. When I eventually had to do the statistical analysis I discovered that the statistical package had been developed by none other than Johann Schepers.

2. What do you appreciate about Johann Schepers as a researcher?

GR: What stands out is his academic caution in the interpretation of research data. If different interpretative options are available, he opts for the most cautious alternative. This is also visible in the approach he has developed to factor analysis where a clear-cut rationale is underlying the procedure, which is not always the case in procedures reported in the research literature.

WS: His scientific approach to problems - all problems in his world. His conviction that anything can be measured (even religious conviction). He anchors everything theoretically. Everything he does has a logical explanation. His highly meticulous approach to research (and study guidance)

FC: As a co-supervisor/co-researcher with Prof Schepers I was astonished by his absolute mastery of complex quantitative techniques. I was not able to perform at his level, but he never made me feel inferior or inadequate. He is always the gentleman, even as a researcher.

DdB: His appreciation of strong psychological theory. His insistence on methodological rigour. "The best statistical treatment in the world cannot inform you about something that you don't have in the data!" His insistence that a research finding should make sense from a theoretical and logical perspective. His ability to research widely, yet dig deeply in each area that he researches. His technical and analytical mastery of multivariate statistical techniques. His patience in explaining complex statistical methods to confused students. His keen interest in his colleagues' research.

AS: His wide field of interest, including a particular understanding of neurological and physiological systems. His inquiring thought processes. His modesty. His recognition that man does not have all the answers, and that no knowledge is final. His love of pure Afrikaans and the accompanying drive to promote Afrikaans as a subject language. His constant quest for, and design of, reliable measuring instruments and procedures through the reading of recent literature, his thorough assessment of dissertations, reports and articles, his stimulating class presentations, and his admirable understanding of quantitative methodologies while recognising the value of qualitative research.

LvV: He forces his colleagues and students to THINK and figure things out for themselves, to understand WHY they do certain things. He thus refrains from spoon-feeding people. He expresses himself eloquently and in straightforward terms when reporting and discussing results. He is extremely meticulous, almost pedantic in his approach. He has an ability to direct research and provide solutions to seemingly "unsolvable" problems. He has an ability to interpret the statistical authenticity of data at a glance.

3. What is the one thing that makes Johann Schepers unique (without it he would not be the same)

DdB: Prof Johann is a true scholar - he needs intellectual stimulation. He must know, not just empirically, but also analytically. Showing him a result is not enough, the result must also be explained. In his quest for knowledge he remains humble and respectful of the scientific process and others participating in it. All in all, what makes him unique is his technical mastery of complex statistical techniques with unparalled psychological insight and profound knowledge of psychological theory. This combination makes him the outstanding academic he is.

LvV: He has an incredibly focused intellect. When he decides to concentrate on a task at hand or on a conversation, he seems to be able to give it $100 \%$ focus and attention, without getting sidetracked by peripheral issues. His extraordinary memory also facilitates his phenomenal ability to analyse problems in an inductive or deductive way and to suggest unique solutions regarding the statistical analyses. Although he is always constructively critical, he is always humane - in this he treats everyone with respect.

FC: As Professor in psychometrics you would think that his greatest strength would be his skill in quantitative research [I overheard the Harvard Professor, Bob Rosenthall, referring to him as a cutting-edge thinker in the field of psychometrics]. However, as I got to know him better I came to realise that what truly makes him unique is his astonishing general knowledge, which covers mathematics, statistics, the social sciences and the humanities (he is able to read classical Greek and Hebrew).

WS: His amazing encyclopedic knowledge which he gladly shares with everyone who crosses his path, and wants to listen.

GR: Prof Schepers to me is the most under-estimated researcher in the broad field of Psychology. Owing to his inclination towards excellence he has made significant contributions in this field that were, in my opinion, not always sufficiently recognised (or perhaps understood due to their technical nature) in the South African and international context.

AS: In the midst of an exceptionally successful research profile he maintains his gentle, and empathic, fatherly way with people, his belief in the goodness of mankind, his humility, and his faith.

4. What do you wish future researchers to gain from Johann Schepers' legacy?

WS: The continued existence of the empirical model in South Africa. The building and integration of theory which is derived from his results and methods. To keep psychometrics in South Africa at the world-class standard where it currently is, thanks to him. Somebody in Psychology needs to inherit his incredible memory.

DdB: His deep appreciation of the rigour of the scientific method. His appreciation and demonstration of the importance of statistical expertise in psychological research. His appreciation of the importance of scientific explanation against the background of psychological theory and logic.

AS: Retention of factor analysis, comparative statistics, regression analysis, canonical correlations and much more in psychological research: pure and flawless language usage, critical thinking, the use and expansion of quantitative methodology without putting down alternative methods, wide interests, publication of findings, generation of new psychometric tests and/or revision of existing ones, the constant studying of international literature, and maintaining modesty, empathy and support to students on all levels.

GR: The list of things that we as junior researchers can learn from Prof Schepers is most probably endless. But if I have to single out a few things, they would be the following: Firstly, the wide basis of his knowledge and the depth of understanding across the whole spectrum of his knowledge is astounding. Secondly, his critical reasoning ability and his ability to integrate knowledge across different areas in the field of psychology are second to none. Thirdly, his critical reasoning ability as a scientist puts him in a different class altogether. Fourthly, his vast knowledge in the field, his ability to keep up with development across the field combined with his phenomenal memory make him a super scholar and a psychometrician of unsurpassed standing in South Africa.

LvV: Although he is the single parent of factor analysis in South Africa, and thus has a natural tendency to apply factor-analytic techniques to explore the properties and utility of psychological measures, he always attempted to find the best statistical solution for a problem presented to him. His ability to answer a problem by matching the most appropriate statistical technique to the unique demands of a research problem is without par. Striving to acquire the competence of having a focused, well-delineated approach to dissect and solve complex research problems. Progressing towards answering the research problem whilst not being distracted by peripheral "noise". To stick to the point and only to what is known.

FC: The idea that research can be both elegant and a joyous experience. 
Participants took notes during their interviews and reported back a compelling story, quote or reminiscence they had identified, to the larger group. This stimulated even more stories, insights and discussions that left us in awe of his stature. By means of a narrative analysis we subsequently extracted themes we believed were representative of the essence of Johann Schepers.

We did not identify the most dominant themes, as is normally done in an appreciative inquiry (Watkins \& Mohr, 2001), but opted to interpret the entire list in order to construct a positive image (profile) of him. After deliberation, the group identified the following clusters that could be utilised for the construction of such a profile. Following a process of synthesis marked by a number of iterations (to avoid duplication of information) a structured profile was created consisting of personality, cognition, skills and attitudes. The integrated outcome is represented in Table 2 .

TABLE 2

\section{Profile of Johann M. Schepers}

\section{PERSONALITY}

When we think about Professor Johann Schepers, we think of a softspoken true gentleman, an empathic, generous and fatherly figure who believes the best of people and never fails to give inspiration, encouragement and support where needed. Yet he has a subtle and sharp wit. In spite of a phenomenal academic profile, there is no sign of academic arrogance. This does not mean that Prof Johann cannot be assertive when he knows he is right. He can engage without inhibition in fascinating debates regarding appropriate research designs and scientific methods, with world-class finesse. He is steadfast in his religion and his wisdom is always apparent.

Prof Johann might be described as somewhat introverted, but he is able and willing to engage in long and animated discussions about things that interest him. However, he does not tolerate sloppiness, dishonesty, rudeness and unfairness. Prof Johann is very serious about his work - his attention to detail is legendary and he is satisfied with excellence only. He is open to new ideas, but like a true scientist approaches them with a sceptical attitude. If you can convince Prof Johann of the merits of your new idea, chances are the idea will bear fruit.

I am not sure what his personal projects and ambitions are, but I guess one of them is to be as good an academic as he can be. In this he succeeds cum laude. He sets a shining example in his day-to-day behaviour that others may follow.

\section{COGNITION}

Prof Johann's brilliant mind is a questioning one, and in true Kelly tradition he can be regarded as a Scientist who analyses, hypothesises, gathers data, evaluates and comes to conclusions, always accepting the possibility of alternative explanations. He has a deep and insightful understanding of his fields of interest and an excellent memory to boot, all of which accounts for his encyclopaedic knowledge of so many fields of psychology.

His ability to see flaws in a study where others see none, is legendary. Many a presenter at local Psychology conferences can testify that they experience a bit of panic when Prof Johann raises his hand to make a comment or ask a question. To his credit, the questions and comments are always presented with the aim of shedding light on areas that are unclear or to give an alternative perspective. Prof Johann never aims to show his superior knowledge at the expense of another academic.

His deep understanding of complex statistical techniques, combined with his encyclopaedic psychological knowledge allows him to design studies and ask questions of the data that others overlook.

As a true scientist Johann Schepers has an enquiring outlook on the laboratory of the social scientist, which, in his words, is "all around us" (compared to natural scientist who can conduct his investigations between four walls). He has a wide spectrum and depth of knowledge he has the ability to conduct in-depth debates around diverse topics related to evolution, religion, natural history, philosophy, languages, medicine, neurology, physiology, politics and many others. As a researcher his publication record bears testimony to his broad sphere of interest in the behavioural sciences. Here one can think of his research on, to name but a few, the effects of antihistamine medication on drivers' vigilance, measures to re-employ the brain injured, and complex factor-analytical formulae.

\section{SKILLS}

Prof Johann's skills move beyond the ordinary. He is a specialist mathematician and statistician and can also be regarded as the father of psychometrics in South Africa. In addition he has a profound knowledge of the Bible which he analyses, where possible, in true scientific fashion. His skills are not limited to analyses but indeed all research is undertaken against the background of an extensive theoretical foundation which guides the research question and hence the research methodology. His interest in and knowledge of neuropsychology and individual differences ensure stimulating academic discussions and lectures.

Whereas many psychometricians are satisfied with working with already established formulae, Prof Johann seeks an analytical understanding and mathematical proof of the formula. Seeing is not enough - understanding is required. This skill contributes to the quality of his thinking and research.

He has the uncanny ability to switch conversations between different and very diverse problems of high complexity within a matter of minutes. He always argues the principle, rather than the person. His analytical mind, together with his attention to detail, makes him a formidable supervisor of post-graduate students - rarely could they escape his seemingly casual, but incisive scrutiny of their sense-making of either literature studies or statistical data. His ability to focus on his field of expertise, albeit seemingly dogmatic, caused him to specialise in complex research design and data analysis ventures.

\section{ATTITUDES}

For Prof Johann research goes beyond the supervision of Master's and doctora degree students; research, to the generation of scientifically based knowledge for future generations. In striving for excellence he maintains research circumspection and always remains the cautious, uncompromising scientist. Although he could find deep pleasure in completing complex challenges, Johann Schepers is a man of true humility. He is quietly assertive. His perseverance in overcoming stumbling blocks bore great results and garnered many research accolades. He displays a knack for finding flaws in apparently flawless research designs and data-analyses even when these are presented by experienced and renowned researchers at national and international conferences.

\section{DISCUSSION AND CONCLUSION}

The appreciative inquiry served to highlight several salient aspects of Johann Schepers as scientist/researcher, teacher and person. In the paragraphs that follow we discuss the essence of his contribution.

His legacy as a scientist/researcher is most clearly visible in the volume of tests, questionnaires, texts on test construction and factor analysis, and many articles in scientific journals which he was responsible for. While impressive, his students will remember him as a teacher.

His legacy as a teacher is most clearly visible in the number of "prominent" researchers who studied under his supervision and who now in turn supervise the work of a next generation of researchers. As is evident from this study, his legacy is captured in stories which describe "the Schepers way of doing it". Moreover, they will remember him for inspiring them to study statistics, for his refusal to compromise on the correct use of language, be it English or Afrikaans, and for the fact that he was never the entertainer, yet always captivating and awe-inspiring.

The preceding paragraphs focused on the explicit manifestation of his legacy. Yet, the most important part is latent. The combination of his technical acumen, teaching skills and humanness make the whole something more than the sum of the parts.

Trying to analyse him in terms of a list of distinctive traits and characteristics does not capture the essence of him as a person, or the extent of his contribution. It is in the stories that are told about him that the authentic Johann Schepers emerges. These stories highlight the fact that it is through his encounters with people that he brought about a change in them. 
What we will remember Johann Schepers for, is his example of how to engage with science, students and people in general. His legacy needs to be protected and nurtured.

\section{REFERENCES}

Bloom, H. (2002). Genius: A mosaic of one hundred exemplary creative minds. London: Fourth Estate.

Cameron, K.S., Dutton, J.E., \& Quinn, R.E. (2003). Foundations of positive organisational scholarship. In: K.S. Cameron, J. E. Dutton \& R.E. Quinn. (eds). San Francisco: BerrettKoehler.

Cooperrider, D. L. (1999). Positive image, positive action: The affirmative basis of organizing. In S. Srivastva \& D. L. Cooperrider (eds.). Appreciative management and leadership. Euclid, Oh: Williams Custom.

Cooperrider, D.L., \& Avital, M. (2004). Introduction: Advances in appreciative inquiry - constructive discourse and human organization. In D.L. Cooperrider \& M. Avital (eds.). Constructive discourse and human organization. New York Elsevier.

Cooperrider, D.L., Whitney, D., \& Stavros, J.M. (2003). Appreciative inquiry handbook. Bedford Heights, OH: Lakeshore.
Cooperrider, D. L., \& Srivastva, S. (1987). Appreciative inquiry in organizational life. Research in Organizational Change and Development, 1: 129-169.

Fredrickson, B.L. (2003). Positive emotions and upward spirals in organizations. In K.S. Cameron, J.E. Dutton, \& R.E. Quin (eds.). Positive organizational scholarship: Foundations of a new discipline. San Francisco: Berrett-Koehler.

Gardner, H., Csikszentmihalyi, M., \& Damon, W. (2001). Good work: When excellence and ethics meet. New York: Basic Books.

Madeline, L., \& Martin, M. (2006). Picasso and Africa. Cape Town: Bell-Roberts.

O'Hara, S. (1985). Assessment of field dependence - field independence. Unpublished doctoral dissertation. Johannesburg: Rand Afrikaans University.

Haidt, J., \& Keltner, D. (2004). Appreciation of beauty and excellence. In C. Peterson, \& M.E.P. Seligman (eds.) Character strengths and virtues: A handbook and classification. Oxford: Oxford University Press.

Watkins, J.M., \& Mohr, B.J. (2001). Appreciative inquiry: Change at the speed of imagination. San Francisco: Jossey Bass/Pfeiffer.

Whitney, D., Cooperrider, D., Trosten-Bloom, A., \& Kaplin, B.S. (2002). Encyclopedia of positive questions. Euclid, OH: Lakeshore Communications.

Whitney, D., \& Trosten-Bloom, A. (2003). The power of appreciative inquiry: A practical guide to positive change. 